\title{
Effect of gas cooking on lung function in adolescents: modifying role of sex and immunoglobulin $\mathrm{E}$
}

G M Corbo, F Forastiere, N Agabiti, V Dell'Orco, R Pistelli, M L Aebischer, S Valente, C A Perucci

\begin{abstract}
Background-A study was undertaken to investigate the effect of gas cooking on the lung function of adolescents while considering serum IgE level as a possible effect modifier.

Method-The cross sectional study was performed in 702 subjects aged 11-13 years from primary and secondary schools in Civitavecchia and Viterbo ( Latium region in Central Italy), categorised according to how often they were in the kitchen while the mother cooked (never, sometimes, often). Data were collected by questionnaire and lung function was measured by spirometric tests. Bronchial hyperresponsiveness was evaluated by the methacholine test, atopic status by a skin prick test, and a blood sample was collected to determine serum IgE levels. The results were analysed separately for boys and girls. Multiple regression analysis was performed, taking functional parameters $\left(\mathbf{F E V}_{1}, \quad \mathbf{F E V}_{1} / \mathbf{F V C}, \mathbf{F E F}_{25-75}\right.$, $\left.\mathbf{F E F}_{50}, \mathbf{F E F}_{75}\right)$ as the dependent variables and age, height, parental smoking, and father's education as independent variables.
\end{abstract}

Results-There was no association between time spent in the kitchen and lung function level in boys, but a reduction in lung function was detected in girls which was statistically significant for $\mathbf{F E F}_{75}$ (sometimes $\mathbf{- 1 0 . 3 \%}$, often $-\mathbf{1 1 . 1 \%}$ ). After stratifying boys and girls into four groups on the basis of the IgE serum level (below and above the median value of IgE), the reduction in lung function was significant in girls with a high IgE value whereas no significant deleterious effects were evident in girls with a low IgE value or in boys with either a low or high IgE. The results remained substantially unchanged after excluding girls with a response to methacholine below the concentration of $4 \mathrm{mg} /$ $\mathrm{ml}$, asthmatic patients, and those with positive skin prick tests.

Conclusion-Gas cooking has a harmful effect on the lung function of girls with a high serum level of IgE. We do not know whether serum IgE, a marker of allergic susceptibility, is a simple indicator that an inflammatory process is in progress or whether it is involved in the pathogenesis of injury leading to bronchial obstruction. (Thorax 2001;56:536-540)

Keywords: gas stoves; lung function; adolescents; IgE
A 1977 study by Melia and collegues ${ }^{1}$ suggested an increase in respiratory illness among schoolchildren exposed to gas cooking. Since then several studies have been performed on the health effects of nitrogen dioxide $\left(\mathrm{NO}_{2}\right)$, of which gas appliances constitute the major indoor source. A meta-analysis including 11 studies on the health effect of $\mathrm{NO}_{2}$ found that the relative risks of lower respiratory tract illnesses in children associated with exposure to a $30 \mu \mathrm{g} / \mathrm{m}^{3}$ increase in $\mathrm{NO}_{2}$ ranged from 0.63 to 1.53 with an overall estimate of 1.18 (95\% CI 1.1 to 1.3$),{ }^{2}$ although a more recent study failed to find an association between exposure to $\mathrm{NO}_{2}$ and lower respiratory tract illnesses. ${ }^{3}$ The effect of $\mathrm{NO}_{2}$ on pulmonary function in children, however, is more controversial. Some studies have shown statistically significant decrements in pulmonary function measures ${ }^{45}$ associated with gas cooking, while others have failed to confirm these findings. ${ }^{6}$ Recently, the relationship of adult respiratory symptoms to cooking fuel used in childhood has been investigated in a cohort study. ${ }^{7}$ No association was found between the incidence or prognosis of asthma, allergic sensitisation, and the use of gas for cooking in childhood or adulthood. However, the use of gas for cooking in adulthood was associated with reduced ventilatory function in men.

Jarvis et al reported adverse effects of the use of gas stoves on respiratory health and lung function in young women. Gas cooking was not associated with an increased prevalence of atopy (as specific IgE) or total serum IgE level, although the risk of respiratory symptoms was increased more in women who were atopic than in non-atopic women. A possible interaction between gas stove use and atopy was suggested, but the confidence intervals were too wide to show a significant effect modification. In a subsequent paper Jarvis et $a l^{9}$ reported data collected as part of an international study from 11 countries for a total of 5561 men and 6029 women. They found that the association between gas cooking and symptoms and lung function was not consistently observed in the entire population. Again, women who were atopic were at a greater risk of symptoms if they cooked with gas than those who were nonatopic, although again this difference did not reach statistical significance. Recently, a cross sectional Dutch study in adults ${ }^{10}$ found that the exposure to gas cooking was associated with an increase in bronchial responsiveness in subjects with high total IgE levels. 
We studied a sample of adolescents to evaluate whether exposure to gas stoves is associated with a lung function decrement, in particular among subjects with high total IgE levels.

\section{Methods}

DATA COLLECTION

In 1990-1 we conducted a survey of respiratory disease in a population sample of schoolchildren living in two areas in the Latium region, Italy. Details of the population selection have been reported previously. ${ }^{11}$ All children attending the fifth grade in seven randomly chosen primary schools in various communities of the Latium region and all of the adolescents attending the six nearby secondary schools were invited to participate. Parents were asked to complete a self-administered questionnaire adapted from the American Thoracic Society questionnaire on children which included a question on the type of stove used most frequently for cooking. ${ }^{12}$ Asthma was defined as either physician diagnosed asthma (ATS question 29A) or at least three of the following: wheeze with colds (Q17A), wheeze apart from colds (Q17B), dyspnoea associated with wheeze (Q18A), and wheeze after exercise (Q19). During the examination each subject was directly interviewed by a physician using a structured questionnaire about the environment at home. A specific question asked if the subject was in the kitchen while the mother cooked (never, sometimes, often).

LUNG FUNCTION MEASUREMENTS

A physical examination was performed in order to exclude children in whom spirometric testing was contraindicated or not feasible; a baseline pulmonary function test (water filled spirometer, Biomedin, Padua, Italy) was performed by all others. Each child had at least three recorded attempts with a noseclip. Forced vital capacity (FVC), forced expiratory volume in one second $\left(\mathrm{FEV}_{1}\right)$, forced expiratory rates at $50 \%\left(\mathrm{FEF}_{50}\right), 75 \%\left(\mathrm{FEF}_{75}\right)$, and between $25 \%$ and $75 \%\left(\mathrm{FEF}_{25-75}\right)$ of vital capacity were measured. The best FVC and $\mathrm{FEV}_{1}$ values were recorded while $\mathrm{FEF}_{75}$ and $\mathrm{FEF}_{25-75}$ were derived from the best curve, defined as the greatest sum of FVC and $\mathrm{FEV}_{1}$.

\section{METHACHOLINE TEST}

Bronchial responsiveness was evaluated by the methacholine test. Only children with $\mathrm{FEV}_{1}$ $>80 \%$ of the predicted value and with an $\mathrm{FEV}_{1} / \mathrm{FVC}$ ratio $>70 \%$ performed the methacholine test. This test involved 2 minute tidal volume breathing aerosols delivered by a 646 DeVilbiss nebuliser (DeVilbiss, Somerset, UK). Phosphate buffered saline (PBS) solution was inhaled first, followed by increasing concentrations of methacholine $(0.06,0.25$, $1.0,4.0,16.0$, and $64 \mathrm{mg} / \mathrm{ml}) . \mathrm{FEV}_{1}$ was measured at 30 and 90 seconds after each inhalation, and the change from the postsaline baseline was calculated. Inhalations were continued until the $\mathrm{FEV}_{1}$ had fallen by $20 \%$ or the maximum concentration of methacholine had been administered. The result of the test was given as the concentration of the drug sufficient to cause a $20 \%$ decrease in $\mathrm{FEV}_{1}\left(\mathrm{PC}_{20} \mathrm{FEV}_{1}\right)$. This index was calculated by interpolation from the logarithmic concentration-response curve according to a method widely used in clinical practice.

\section{SKIN TESTS}

Skin prick tests were used to evaluate atopic status. Eight extracts of common allergens were tested (Bayrofarm, Milan Italy): Dermatophagoides pteronyssinus, grass, mugwort, Parietaria species, cat fur, Olea species, trees, Alternaria species. Histamine dihydrochloride $(10 \mathrm{mg} /$ $\mathrm{ml}$ ) and diluent were used as positive and negative controls, respectively. After $15 \mathrm{~min}$ utes the weals were outlined and the markings transferred to $\mathrm{mm}^{2}$ paper using a tape. Weal size was calculated by multiplying the long axis by its perpendicular, with an area of $>3 \mathrm{~mm}^{2}$ being considered positive.

\section{IGE DETERMINATIONS}

The total sample examined in the 2 years of the survey included 2439 schoolchildren. In the last 5 months of the survey the subjects were asked to give blood samples for a number of investigations, including the measurements of serum levels of IgE. Parents were asked to give written consent. This written consent was obtained by 997 of the 1220 subjects who were studied in the last 5 months of the survey. Serum samples were collected from 901 subjects and frozen at $-70^{\circ}$. All serum IgE levels were measured in the same laboratory (Red Cross, Rome) using the PRIST technique. Samples were run in duplicate and the mean of the two $\operatorname{IgE}$ determinations was used in the present analysis.

DATA ANALYSIS

The sample included 901 subjects with total serum IgE determinations. Several exclusions were made in order to obtain a sample with complete data on lung function, IgE, and presence in the kitchen. Subjects whose mothers did not use a gas stove for cooking were excluded $(n=28,3.5 \%)$, and information about the presence in the kitchen was missing for 140 subjects. Thirty one subjects were unable to undergo spirometric testing, leaving a final sample of 702 subjects ( 376 boys) for analysis. The excluded sample was fairly equal to the final sample with regard to sex (boys $55.9 \%$ v $53.6 \%$ ), age (13.4 $v 13.34$ years), prevalence of positive skin tests $(26.3 \%$ v $26.3 \%)$, and asthma $(8 \%$ v $7.4 \%)$.

Comparisons were made using ANOVA for continuous data and $\chi^{2}$ and $\chi^{2}$ for trend were used for categorical data.

Lung function was analysed by linear regression analysis. The functional parameter $\left(\mathrm{FEV}_{1}, \mathrm{FEV}_{1} / \mathrm{FVC}, \mathrm{FEF}_{25-75}, \mathrm{FEF}_{50}, \mathrm{FEF}_{75}\right)$ was the dependent variable and sex, age, height, parental smoking, and father's education were independent variables. The effect of being in the kitchen while the mother cooked was tested, including in the model two dummy variables taking subjects who never went into the kitchen as reference. Because of the heteroscedastic relationship between lung function and some of these predictors, the lung function 
measures, age, and height were log transformed. Results were expressed as the estimated differences in lung function by percentage - that is, by taking the regression coefficient as exponent, subtracting 1 , and multiplying the results by 100 . Confidence intervals were also expressed as percentages.

As the first step, regression analysis on the effect on lung function of being in the kitchen was performed on the whole sample. The effect modification of sex and $\operatorname{IgE}$ was tested, including interaction terms in the model. IgE was included as a categorical variable (low and high - that is, below and above the median value). In a second step boys and girls were analysed separately. Lastly, we tested the effect in girls and in boys with high and low total IgE of being in the kitchen while the mother cooked.

\section{Results}

Table 1 shows the descriptive characteristics of the children according to sex. As expected, girls spend time in the kitchen more frequently than boys $(\mathrm{p}<0.001)$. Boys were significantly older (13.4 $v 13.2$ years, $\mathrm{p}=0.001)$, with a higher prevalence of asthma $(10.6 \% \quad v \quad 3.7 \%$, $\mathrm{p}=0.0000)$ and skin test positivity $(29.7 \%$ v

Table 1 Characteristics of the sample by sex

\begin{tabular}{|c|c|c|c|c|}
\hline & \multicolumn{2}{|l|}{ Boys } & \multicolumn{2}{|l|}{ Girls } \\
\hline & No & $\%$ & No & $\%$ \\
\hline No of subjects & 376 & & 326 & \\
\hline \multicolumn{5}{|l|}{ Habitual presence in the kitchen } \\
\hline Never & 113 & 30.1 & 56 & 17.2 \\
\hline Sometimes & 222 & 59.0 & 216 & 66.3 \\
\hline Often & 41 & 10.9 & 54 & 16.6 \\
\hline Mean age (years) & & 13.4 & & 13.2 \\
\hline \multicolumn{5}{|l|}{ Father's education (years) } \\
\hline$<6$ & 113 & 30.1 & 106 & 32.5 \\
\hline $6-8$ & 147 & 39.1 & 122 & 37.4 \\
\hline $9-13$ & 101 & 26.9 & 72 & 22.1 \\
\hline$>13$ & 15 & 4.0 & 21 & 6.4 \\
\hline Parental smoking & 237 & 63.0 & 200 & 61.3 \\
\hline Asthma & 40 & 10.6 & 12 & 3.7 \\
\hline Methacholine $\mathrm{PC}_{20} \leqslant 4 \mathrm{mg} / \mathrm{ml} \rrbracket$ & 44 & 12.2 & 32 & 10.4 \\
\hline Skin reactors & 111 & 29.7 & 74 & 22.8 \\
\hline Geometric mean IgE (IU/ml) & & 57.0 & & 44.5 \\
\hline $\mathrm{FEV}_{1}(\mathrm{l})^{\star}$ & & 3.11 & & 3.11 \\
\hline $\mathrm{FEV}_{1} / \mathrm{FVC}(\%)^{\star}$ & & $89 \%$ & & $91 \%$ \\
\hline $\mathrm{FEF}_{25-75}(1 / \mathrm{s})^{\star}$ & & 3.86 & & 4.00 \\
\hline $\operatorname{FEF}_{50}(1 / \mathrm{s})^{\star}$ & & 4.24 & & 4.35 \\
\hline $\mathrm{FEF}_{75}(1 / \mathrm{s})^{\star}$ & & 2.24 & & 2.45 \\
\hline
\end{tabular}

*Adjusted for age and height. $\$ 16$ boys and 19 girls did not perform the test.

Table 2 Percentage changes in lung function in girls and boys according to habitual presence in the kitchen

\begin{tabular}{|c|c|c|c|c|}
\hline & \multicolumn{2}{|l|}{ Boys } & \multicolumn{2}{|l|}{ Girls } \\
\hline & $\%$ & $95 \% C I$ & $\%$ & $95 \% C I$ \\
\hline \multicolumn{5}{|l|}{$\mathrm{FEV}_{1}$} \\
\hline Sometimes & 0.01 & -2.85 to 2.39 & -1.28 & -4.64 to 2.19 \\
\hline Often & 1.06 & -3.00 to 5.30 & -0.58 & -4.90 to 3.94 \\
\hline \multicolumn{5}{|l|}{$\mathrm{FEV}_{1} / \mathrm{FVC}$} \\
\hline Sometimes & 0.45 & -0.86 to 1.79 & -1.12 & -2.82 to 0.61 \\
\hline Often & -0.09 & -2.12 to 1.99 & -1.99 & -4.16 to $0.22^{\star}$ \\
\hline \multicolumn{5}{|l|}{$\mathrm{FEF}_{25-75}$} \\
\hline Sometimes & 2.13 & -2.53 to 7.02 & -4.83 & -10.43 to 1.11 \\
\hline Often & 5.38 & -2.03 to 13.35 & -5.95 & -13.01 to 1.68 \\
\hline \multicolumn{5}{|l|}{$\mathrm{FEF}_{50}$} \\
\hline Sometimes & 1.48 & -3.43 to 6.64 & -4.56 & -10.37 to 1.63 \\
\hline Often & 5.27 & -2.60 to 13.78 & -7.45 & -14.63 to $0.34^{\star}$ \\
\hline \multicolumn{5}{|l|}{$\mathrm{FEF}_{75}$} \\
\hline Sometimes & 4.35 & -2.98 to 12.23 & -10.34 & -18.36 to $-1.54^{\star \star}$ \\
\hline Often & 4.41 & -6.80 to 16.96 & -11.10 & -21.18 to $0.26^{\star}$ \\
\hline
\end{tabular}

Models were adjusted for age, height, father's education, parental smoking. ${ }^{\star} \mathrm{p}<0.10 ;{ }^{\star \star} \mathrm{p}<0.05$.
$22.8 \%, \mathrm{p}=0.04)$. The serum IgE level was also higher in boys (geometric mean $57.0 \mathrm{IU} / \mathrm{ml} v$ $44.5 \mathrm{IU} / \mathrm{ml}, \mathrm{p}=0.04)$. No significant sex differences were found for father's education, exposure to parental smoking, and bronchial response to methacholine. Boys tended to have lower lung function than girls. Adjusting for age and height, $\mathrm{FEV}_{1}$ did not differ in boys and girls (3.11 1 v 3.11 1), whereas $\mathrm{FEV}_{1} / \mathrm{FVC}$ ratio $(89 \%$ v $91 \%, \mathrm{p}=0.001), \mathrm{FEF}_{25-75}(3.86 \mathrm{l} / \mathrm{s}$ v $4.00 \mathrm{l} / \mathrm{s}$, $\mathrm{p}=0.03), \mathrm{FEF}_{50}(4.24 \mathrm{l} / \mathrm{s} v 4.35 \mathrm{l} / \mathrm{s}, \mathrm{p}=0.07)$, and $\mathrm{FEF}_{75}(2.24 \mathrm{l} / \mathrm{s} v 2.45 \mathrm{l} / \mathrm{s}, \mathrm{p}=0.001)$ were significantly lower in boys than in girls.

The overall analysis suggested an effect modification by sex. A formal test of interaction between presence in the kitchen and sex was significant with regard to $\mathrm{FEF}_{25-75}$ (sometimes: $p=0.05$, often: $p=0.01$ ), $\mathrm{FEF}_{50}$ (sometimes: $p=0.09$, often: $p=0.016$ ), and $\mathrm{FEF}_{75}$ (sometimes: $p=0.009$, often: $p=0.05$ ). At the same time, the effect modification of IgE was marginally significant only for $\mathrm{FEF}_{50}$ (often: $\mathrm{p}=0.04)$.

We then analysed boys and girls separately. In boys, presence in the kitchen had no effect on lung function and there was no statistically significant interaction between presence in the kitchen and IgE levels. However, girls who were often present in the kitchen tended to have lower lung function than those who were only in the kitchen sometimes (table $2 ; \mathrm{p}$ for trend: $\mathrm{FEV}_{1}=0.93, \mathrm{FEV}_{1} / \mathrm{FVC}$ ratio $=0.03, \mathrm{FEF}_{25-75}$ $=0.08, \mathrm{FEF}_{50}=0.048$, and $\left.\mathrm{FEF}_{75}=0.02\right)$. This reduction was statistically significant for $\mathrm{FEF}_{75}$. When the effect of IgE level was formally tested in the linear regression analysis, statistically significant interaction terms were found for $\mathrm{FEV}_{1}$ (sometimes $\mathrm{p}<0.02$, often $\mathrm{p}<0.01$ ) and $\mathrm{FEF}_{50}$ (sometimes $\mathrm{p}<0.01$, often $\mathrm{p}<0.005$ ).

We therefore stratified boys and girls into four groups on the basis of their serum IgE level, below and above the median value of $\mathrm{IgE}$ $(65.34 \mathrm{IU} / \mathrm{ml}$ and $48.56 \mathrm{IU} / \mathrm{ml}$, respectively; table 3). Boys with either a high or low serum $\mathrm{IgE}$ level showed no reduction in lung function when present in the kitchen. However, in girls with a high serum IgE level there was a significant reduction in lung function while no significant deleterious effects were seen in girls with a low IgE level. With the exception of $\mathrm{FEF}_{75}$, the percentage reduction was greater in girls who were often present in the kitchen.

We performed a separate analysis in which we excluded girls with a $\mathrm{PC}_{20} \mathrm{FEV}_{1} \leqslant 4 \mathrm{mg} / \mathrm{ml}$ $(n=20)$, those with asthma $(n=7)$, and girls with at least one positive skin test $(n=53)$, but no substantial change in the results was observed.

\section{Discussion}

Most of the studies on the use of gas stoves have made a comparison between subjects who used gas stoves and those who used other stove types such as electric cookers. In Italy the use of gas stoves is so common $(96.5 \%$ in our sample) that we were unable to perform such a comparison. We evaluated habitual presence in the kitchen as an indicator of exposure. Although this could have introduced a misclassification in the exposure assessment as boys may be reluctant to report their presence in the 
Table 3 Percentage changes in lung function in boys and girls according to the level of serum IgE and to the habitual presence in the kitchen

\begin{tabular}{|c|c|c|c|c|c|c|c|c|}
\hline & \multicolumn{4}{|l|}{ Boys } & \multicolumn{4}{|l|}{ Girls } \\
\hline & \multicolumn{2}{|c|}{ High IgE } & \multicolumn{2}{|c|}{ Low IgE } & \multicolumn{2}{|c|}{ High IgE } & \multicolumn{2}{|c|}{ Low IgE } \\
\hline & $\%$ & $95 \% C I$ & $\%$ & $95 \% C I$ & $\overline{\%}$ & $95 \% C I$ & $\overline{\%}$ & $95 \% C I$ \\
\hline \multicolumn{9}{|l|}{$\mathrm{FEV}_{1}$} \\
\hline Sometimes & 2.99 & -0.96 to 7.12 & -3.43 & -6.78 to 0.03 & -4.84 & -9.28 to $-0.19^{\star \star}$ & 2.93 & -2.07 to 8.19 \\
\hline $\begin{array}{l}\text { Often } \\
\text { FEV }_{1} / \mathrm{FVC}\end{array}$ & 1.41 & -4.65 to 7.87 & -0.14 & -5.59 to 5.62 & -5.33 & -10.95 to $0.65^{\star}$ & 5.91 & -0.74 to 13.01 \\
\hline Sometimes & 0.19 & -1.91 to 2.34 & 0.64 & -0.91 to 2.2 & -1.58 & -4.12 to 1.04 & -0.75 & -3.04 to 1.60 \\
\hline $\begin{array}{l}\text { Often } \\
\text { FEF }\end{array}$ & 0.84 & -2.47 to 4.25 & -1.06 & -3.47 to 1.42 & -1.71 & -4.96 to 1.64 & -2.47 & -5.39 to 0.55 \\
\hline \multicolumn{6}{|c|}{ 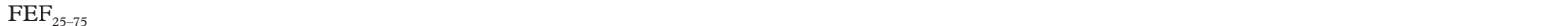 } & & & \\
\hline $\begin{array}{l}\text { Often } \\
\mathrm{FEF}\end{array}$ & 9.91 & -1.81 to 23.02 & $\begin{array}{l}-0.07 \\
1.15\end{array}$ & -8.04 to 11.26 & $\begin{array}{l}-9.49 \\
-11.46\end{array}$ & $\begin{array}{l}-16.93 \text { to }-1.39^{\star \star} \\
-20.79 \text { to }-1.03^{\star \star}\end{array}$ & $\begin{array}{l}-0.10 \\
-0.16\end{array}$ & $\begin{array}{l}-8.32 \text { to } 8.86 \\
-10.65 \text { to } 11.57\end{array}$ \\
\hline Sometimes & 2.91 & -4.66 to 11.09 & -0.15 & -6.32 to 6.42 & -11.09 & -18.62 to $-2.86^{\star \star \star}$ & 3.40 & -5.38 to 13.00 \\
\hline \multicolumn{8}{|c|}{ 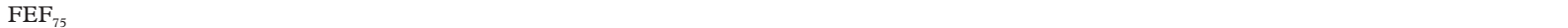 } & -7.61 to 16.23 \\
\hline Sometimes & 4.61 & -7.06 to 17.74 & 3.58 & -5.034 to 12.97 & -15.41 & -25.82 to $-3.54^{\star \star}$ & -5.99 & -17.87 to 7.61 \\
\hline Often & 12.34 & -6.69 to 35.24 & -4.19 & -16.71 to 10.18 & -12.73 & -26.25 to 3.26 & -10.19 & -24.67 to 7.09 \\
\hline
\end{tabular}

Models were adjusted for age, height, father's education, and parental smoking.

kitchen, it could also be biased toward an underestimation of the effect rather than an overestimation. However, this choice allowed us to detect a dose-response effect.

A potential confounder can be considered exposure to passive smoking. We use parental smoking as an indicator of exposure since, in a previous study, ${ }^{11}$ we found that the most important factor determining exposure levelthat is, concentration of urinary cotinine-was current parental smoking, although other factors such as the presence of other smokers in the house, household crowding, and father's education could affect the exposure.

In our sample we found a large disparity in the prevalence of asthma between boys and girls $(10.6 \%$ v $3.7 \%)$ which suggests that a proportion of asthma is being underrecognised in girls. In the 1220 subjects studied in the last 5 years the prevalence of asthma was $10.3 \%$ and $4.9 \%$ in boys and girls, respectively, so a larger proportion of girls with asthma declined to give a blood sample. It is unlikely that this selection could be a source of bias since exclusion of girls with asthma from the analysis did not change the results, although underdiagnosis of asthma in girls could not be excluded.

We found that presence in the kitchen was associated with reduced lung function in girls, the reduction in $\mathrm{FEF}_{75}$ being statistically significant.

In agreement with our data, previous studies in children have shown slight decreases in pulmonary function measures associated with gas cooking or estimated $\mathrm{NO}_{2}$ exposure. ${ }^{45}$ Other authors have failed to find evidence of any detrimental effect on lung function while the incidence of lower respiratory symptoms was significantly increased. ${ }^{6}$ This discrepancy between symptoms and lung function may be due to a delay in the changes in lung function parameters over time, or $\mathrm{NO}_{2}$ might cause bronchiolar damage that is not detected by commonly used lung function tests. ${ }^{6}$ It is also possible that the risk associated with exposure to gas stoves could not be fully accounted for by mean $\mathrm{NO}_{2}$ measurements, and that the peak
$\mathrm{NO}_{2}$ exposure may be the critical factor associated with adverse respiratory effects. This hypothesis was proposed in a recent study which showed that the use of gas stoves was a significant risk factor for respiratory symptoms in children even after adjusting for $\mathrm{NO}_{2}$ levels. ${ }^{13}$

We did not detect an effect of gas stove use on lung function in boys. Previous studies found that the risks associated with $\mathrm{NO}_{2}$ exposure were higher in women than in men, ${ }^{6}{ }^{14}$ although other authors reported that the use of gas cooking was associated with reduced ventilatory function only among men. ${ }^{7}$ We are unable to determine whether this different association in male and female subjects is due to a different degree of exposure or to different mechanical lung properties. ${ }^{15}$ The pulmonary system tends to have a different pattern of response to the environment in males and females. ${ }^{16}$

We found that girls with high serum IgE levels had reduced lung function when exposed to gas stoves whereas girls with low IgE levels did not. This effect remained substantially unchanged when those with positive skin prick tests were excluded. At present the relationship between exposure to gas stoves and atopic status is not fully understood. There is no evidence that $\mathrm{NO}_{2}$ as an indoor pollutant increases the prevalence of atopy, although it has been suggested that it could have an adjunctive effect on the development of an allergy to house dust mites. ${ }^{17}$ Previous studies in adults ${ }^{89}$ and in children ${ }^{13}$ found that the adverse effects tended to be greater in atopic subjects, raising the possibility that atopy could be an effect modifier with atopic subjects being more susceptible to gas stoves. Furthermore, $\mathrm{NO}_{2}$ causes a delayed effect on the bronchial responsiveness in asthmatics, ${ }^{18}$ and in subjects with atopic asthma it enhances the early and late response to allergens. ${ }^{19}$ The mechanisms are not clear, although there are data to support the hypothesis that an activation of granulocytes could be involved. ${ }^{18}$ Nitrogen dioxide can also increase the synthesis of inflammatory cytokine ${ }^{20}$ which could damage the airways leading to bronchial obstruction. Kerkhof et $a l^{10}$ have reported an association between gas cooking and bronchial hyperresponsiveness in 
subjects with high total $\operatorname{IgE}$ levels defined as the highest quartile of distribution. It has been hypothesised that high total IgE levels identify subjects predisposed to asthma who are susceptible to the adverse effect of gas cooking, suggesting that bronchial hyperresponsiveness may represent a possible intermediate between exposure and respiratory symptoms or lung function. In our study the harmful effect of gas stoves did not seem to be mediated by an increase in bronchial responsiveness since exclusion of asthmatics and subjects with bronchial hyperresponsiveness did not change the results. The discrepancy between our results and those reported elsewhere could be due to both a different cut off point in IgE distribution (median $v$ highest quartile) as well as to the different age of the subjects on which the duration of exposure depends. High total serum IgE levels could represent either a marker of susceptibility or may be involved in the pathogenesis of injury leading to bronchial obstruction.

In conclusion, we found that the use of gas stoves has a harmful effect on the lung function of adolescents. The largest effect was seen on mid and end expiratory flow rates $\left(\mathrm{FEF}_{25-75}\right.$, $\mathrm{FEF}_{50}$ and $\mathrm{FEF}_{75}$ ) which are a more sensitive measure of early airways obstruction. Sex and high IgE levels tend to behave as effect modifiers. The clinical significance of such a small effect is not known, and conclusions based on these results could be limited by the cross sectional design and the relatively small size of the sample. However, we suggest that kitchen emissions merit inspection and appropriate ventilation to protect lung health.

1 Melia RJW, Florey C du V, Altman DG, et al. Association between gas cooking and respiratory disease in children. BMF 1977;2:149-52.

2 Hasseblad V, Eddy DM, Kotchmar DJ. Synthesis of environmental evidence: nitrogen dioxide epidemiology studies. F Air Waste Manage Assoc 1992;42:662-71.
3 Samet JM, Lambert WE, Skipper BJ, et al. Nitrogen dioxide and respiratory illness in infants. Am Rev Respir Dis 1993; 148:1258-65.

4 Ware JH, Dockery DW, Spiro A, et al. Passive smoking, gas cooking and respiratory health of children living in six cities. Am Rev Respir Dis 1984;129:366-74.

5 Speizer FE, Ferris B, Bishpo YMM, et al. Respiratory disease rates and pulmonary function in children associated with NO exposure. Am Rev Respir Dis 1980;121:3-10.

6 Neas LM, Dockery DW, Ware JH, et al. Association of indoor nitrogen dioxide with respiratory symptoms and pulmonary function in children. Am f Epidemiol 1991:134: 204-19.

7 Moran SE, Strachan DP, Johnston IDA, et al. Effects of exposure to gas cooking in childhood and adulthood on respiratory symptoms, allergic sensitization and lung function in young British adults. Clin Exp Allergy 1999;29: 1033-41.

8 Jarvis D, Chinn S, Luczynska C, et al. Association of respiratory symptoms and lung function in young adults with use of domestic gas appliances. Lancet 1996;347:426-31.

9 Jarvis D, Chinn S, Sterne J, et al. The association of respiratory symptoms and lung function with the use of gas for cooking. Eur Respir F 1998;11:651-8.

10 Kerkhof M, de Monchy JGR, Rijken B, et al. The effect of gas cooking on bronchial hyperresponsiveness and the role of immunoglobulin E. Eur Respir f 1999;14:839-44.

11 Dell'Orco V,Forastiere F, Agabiti N, et al. Household and community determinants of exposure to involuntary smoking: a study of urinary cotinine in children and adolescents. Am f Epidemiol 1995;142:419-27.

12 Ferris BG. Epidemiology standardization project: children's questionnaire. Am Rev Resp Dis 1978;118:36-53.

13 Garrett MH, Hooper MA, Hooper BM, et al. Respiratory symptoms in children and indoor exposure to nitrogen dioxide and gas stoves. Am 7 Respir Crit Care Med 1998;158:891-5.

14 Pershagen G, Rylander E, Norberg S, et al. Air pollution involving nitrogen dioxide exposure and wheezing bronchitis in children. Int $\mathcal{F}$ Epidemiol 1995;24:1147-53.

15 Landau LI, Morgan W, McCoy KS, et al. Gender related differences in airway tone in children. Pediatr Pulmonol 1993;16:31-5.

16 Demissie K, Ernst P, Joseph L, et al. The role of domestic factors and day-care attendance on lung function of factors and day-care attendance on lung function

17 Colloff MJ, Ayres J, Carswell F, et al. The control of allergens of dust mites and domestic pets: a position paper. Clin Exp Allergy 1992;22(Suppl 2):1-28.

18 Strand V, Salomonsson P, Lundahl J, et al. Immediate and delayed effects of nitrogen dioxide exposure at an ambient level on bronchial responsiveness to histamine in subjects with asthma. Eur Respir F 1996;9:733-40.

19 Tunnicliffe W, Burge P, Ayres J . Effect of domestic concentrations of nitrogen dioxide on airway responses to inhaled allergen in asthmatic patients. Lancet 1994;344:1733-6.

20 Devalia JL, Campbell AM, Sapsford RJ, et al. Effect of nitrogen dioxide on synthesis of inflammatory cytokines expressed by human bronchial epithelial cells in vitro. $A m \mathcal{F}$ Respir Cell Mol Biol 1993;9:271-8. 